\title{
A patient presenting a 22q13 deletion associated with an apparently balanced translocation $t(16 ; 22)$ : An illustrative case in the investigation of patients with low ARSA activity
}

\author{
Osvaldo Artigalás $^{1,2}$, Giorgio Paskulin ${ }^{3,4}$, Mariluce Riegel ${ }^{5}$, Maira Burin ${ }^{6}$, Maria Luiza Saraiva-Pereira ${ }^{6}$, \\ Sharbel Maluf ${ }^{6}$, Andrea Kiss ${ }^{3,4}$ and Ida Vanessa D. Schwartz ${ }^{1,6}$ \\ ${ }^{1}$ Programa de Pós-Graduação em Genética e Biologia Molecular, Departamento de Genética, \\ Universidade Federal do Rio Grande do Sul, Porto Alegre, RS, Brazil. \\ ${ }^{2}$ Unidade de Genética, Hospital da Criança Conceição, Grupo Hospitalar Conceição, \\ Porto Alegre, RS, Brazil. \\ ${ }^{3}$ Programa de Pós-Graduação em Patologia, Universidade Federal de Ciências da Saúde de Porto Alegre, \\ Complexo Hospitalar Santa Casa de Porto Alegre, Porto Alegre, RS, Brazil. \\ ${ }^{4}$ Genética Clínica, Universidade Federal de Ciências da Saúde de Porto Alegre, Porto Alegre, RS, Brazil. \\ ${ }^{5}$ Centro de Terapia Gênica, Centro de Pesquisa Experimental, Hospital de Clínicas de Porto Alegre, Porto \\ Alegre, RS, Brazil. \\ ${ }^{6}$ Serviço de Genética Médica, Hospital de Clínicas de Porto Alegre, Porto Alegre, RS, Brasil.
}

\begin{abstract}
A 10-year-old speechless, mentally deficient male, with low arylsulfatase A (ARSA) activity, and presumably, methachromatic leukodystrophy, underwent genetic evaluation. As the clinical picture was not compatible with this diagnosisan $A R S A$ gene and chromosome analysis were performed, showing the presence of a pseudodeficiency ARSA allele and a de novo apparently balanced $\mathrm{t}(16 ; 22)(\mathrm{p} 11.2 ; \mathrm{q} 13)$ translocation. A deletion on the long arm of chromosome 22 encompassing the ARSA gene, as shown by FISH and array-CGH, indicated a $22 q 13$ deletion syndrome. This case illustrates the importance of detailed cytogenetic investigation in patients presenting low arylsulfatase $A$ activity and atypical/unspecific clinical features.
\end{abstract}

Key words: 22q13 deletion, apparently balanced translocation, ARSA gene, arylsulfatase A pseudodeficiency, metachromatic leukodystrophy.

Received: June 3, 2011; Accepted: March 6, 2012.

Very often genetic syndromes are underdiagnosed, their true incidence remaining unknown through inadequate clinical recognition or incomplete laboratory investigation. In Brazil, this mainly derives from structural deficiencies in the public health system, inappropriate for diagnosing rare diseases (Schwartz et al., 2007). The present report illustrates this, on dealing with the PhelanMcDermid syndrome (22q13 deletion syndrome), with a relatively nonspecific phenotype (Phelan, 2008), and metachromatic leukodystrophy (MLD), all of which requiring careful laboratory investigation to so avoid inaccurate diagnosis (Von Figura et al., 2001; Artigalás et al., 2010).

Send correspondence to Osvaldo Artigalás. Programa de PósGraduação em Genética e Biologia Molecular, Departmento de Genética, Universidade Federal do Rio Grande do Sul, Caixa Postal 15053, Campus Agronomia, 91501-970 Porto Alegre, RS, Brazil. E-mail: artigalas@gmail.com.
Assessment was directed to a 10 -year-old boy presenting low arylsulftase A (ARSA) activity in leukocytes (1.6 nmol/h/mg prot, RV: $5-20)$ and diagnosed as MLD. Nevertheless, his clinical picture was atypical, since, after clinical and radiological evaluation, the prevailing neurological conditions were found to be stable, without signs of neurodegeneration or white matter disorder. The reason for initially determining ARSA activity was not apparent. He was the first son of a healthy, young, non-consanguineous couple, without a family history of genetic diseases. Furthermore, his younger brother was clinically normal. The boy, born through vaginal delivery after a 35 -week pregnancy associated with oligohydramniosis had, received $7 / 8$ APGAR scores. At birth, his weight was 2,630 g, length $46 \mathrm{~cm}$, and head circumference $32 \mathrm{~cm}$. He held up his head at 7 months, sat without support at 18 , and walked without support at 24. Even so, he was unable to develop verbal language. Sphincter control occurred only at 8-years. At 3- 
years, he suffered from absence-type epileptic crises, which progressed to frequent-atonic crises; full control of these was achieved only after 18 months of treatment with phenobarbital, carbamazepine, and valproic acid. Autistic-like behavior was manifest in the form of restricted intuitive social interaction, delayed communication and inflexibility of interests. Physical examination revealed an elongated face, arched eyebrows, long eyelashes, diastasis of the upper central incisors, drooping feet, normal and symmetric deep tendinous reflexes, hypertonia of the lower limbs, and choreoathetosis. Results from subsequent investigations were normal. These consisted of CT brain scan and MRI, the molecular fragile-X syndrome test, blood amino acid thinlayer chromatography, dosage of very-long-chain fatty acids and A and B hexosaminidase activitiy, as well as chitotriosidase in plasma, urinary thin-layer chromatography of amino acids, oligosaccharides and sialosaccharides, and gas chromatography of urinary organic acids.

We determined ARSA activity three times in leukocytes $(0.2,2.1$ and $1.2 \mathrm{nmol} / \mathrm{h} / \mathrm{mg}$ prot, respectively), and twice in fibroblasts $(0.76$ and $0.31 \mathrm{nmol} / \mathrm{h} / \mathrm{mg}$ prot $-\mathrm{RV}$ : $20-50 \mathrm{nmol} / \mathrm{h} / \mathrm{mg}$ prot). All were below the normal range. As apparently sulfatide levels in urine (three different samples) were also low, the presence of the most common ARSA pseudodeficiency allele [p.N350S; c.1524+95A $>\mathrm{G}$ ] was investigated, with positive results. Although the parents had been diagnosed as heterozygous for the PDARSA allele, the patient, on the contrary, was initially misinterpreted as being homozygous for PD-ARSA.

On considering mental deficiency through an unknown cause, we performed a GTG chromosome analysis of peripheral blood leucocytes that revealed an apparently balanced translocation between the short arm of chromosome 16 and the long arm of chromosome 22 $[46, X Y, t(16 ; 22)(p 11.2 ; q 13)]$ in all the 30 metaphases analyzed (Figure 1). Incidentally, the parents presented normal karyotypes. FISH was performed with subtelomeric probes for the short arm of chromosome 16 and the long arm of chromosome 22, together with the DiGeorge/VCFS Probe

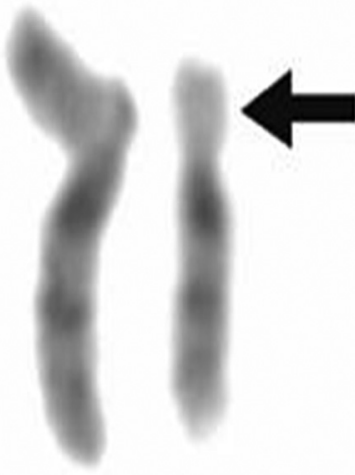

$16 \operatorname{der}(16)$

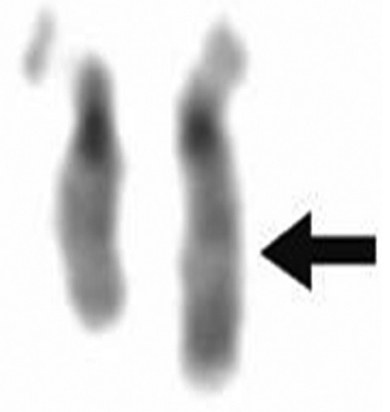

$22 \operatorname{der}(22)$
Figure 1 - t(16;22)(p11.2;q13), GTG-banded der(16), der (22) and their normal homologues. Arrows point to breakpoints.
TUPLE1(22q11.2)/ARSA control probe (22q13.3) (Vysis, Abbott Molecular Inc.). The ARSA (control) probe (22q13.3) and the 22q subtelomeric probe did not hybridize to either der(22) or der(16), whereas theDiGeorge/VCFS Probe TUPLE1 (22q11.2) and the 16p subtelomeric probe were detected on der(22). Array CGH was carried out on propositus DNA, by using an oligonucleotide-based microarray containing about 44,000 60-mer probes (Agilent Human Genome Microarray, customer array design AMADID number 017457). Arrays were analyzed with the AGILENT DNA Microarray Scanner and AGILENT Feature Extraction software (v9.5.3). This revealed a $\sim 1.4 \mathrm{Mb}$ deletion on the long arm of chromosome 22 involving the ARSA and SHANK3 genes (Figure 2). No deletion was detected on chromosome 16. These results were compatible with diagnosis of the 22q13 deletion syndrome. The low ARSA activity, seen in this case, was due to a de novo deletion of the ARSA gene, concomitant with an inherited pseudodeficiency allele.

In spite of variation in expression and severity, patients with the 22q13 deletion syndrome (OMIM \#606232) generally show global developmental delay, generalized hypotonia, autist-like behavior, absence of, or severely retarded speech, normal to accelerated growth, and other minor dysmorphic anomalies (Phelan, 2008). Brain MRI is usually normal or with a thin or morphologically atypical corpus callosum (Philippe et al., 2008). Liver dysfunction has also been observed (Bartsch et al., 2010). Chromosome alterations involving the 22q13 region have been described in over 100 cases (Bisgaard et al. 2009). The most frequent abnormality is a simple terminal deletion (Bonaglia et al., 2011). Nevertheless, in over $30 \%$ of the cases with a 22 q 13 deletion syndrome two or more chromosome studies were required to cytogenetically detect the deletion. Moreover, due to clinical features being unrecognizable to, very subtle and unspecific, in many patients the cytogenetic investigation was not sufficiently profound, thus leading to faulty diagnosis (Phelan, 2008). The SHANK3 gene mapped at 22q13.3 encodes a structural protein found in the postsynaptic density that connects ion channels and receptors on the postsynaptic membrane to the cytoskeleton membrane, in the signal transduction pathway (Durand et al., 2007). Thus, SHANK3 haploinsufficiency appears to be responsible for the main neurological manifestations of the 22 q13 deletion syndrome (Wilson et al. 2008; Bonaglia et al., 2011; Waga et al., 2011).

On contemplating differential diagnosis of low ARSA activity, six conditions should be considered, namely: 1) MLD, 2) ARSA pseudodeficiency, 3) multiple sulfatase deficiency, 4) saposin B deficiency (associated with ARSA deficiency in vivo only) (Von Figura et al., 2001), 5) compound heterozygosity for a null and pseudodeficiency alleles of the ARSA gene (without white matter disease), and 6) the 22q13 deletion syndrome. This syndrome can be associated with reduced ARSA activity, even 


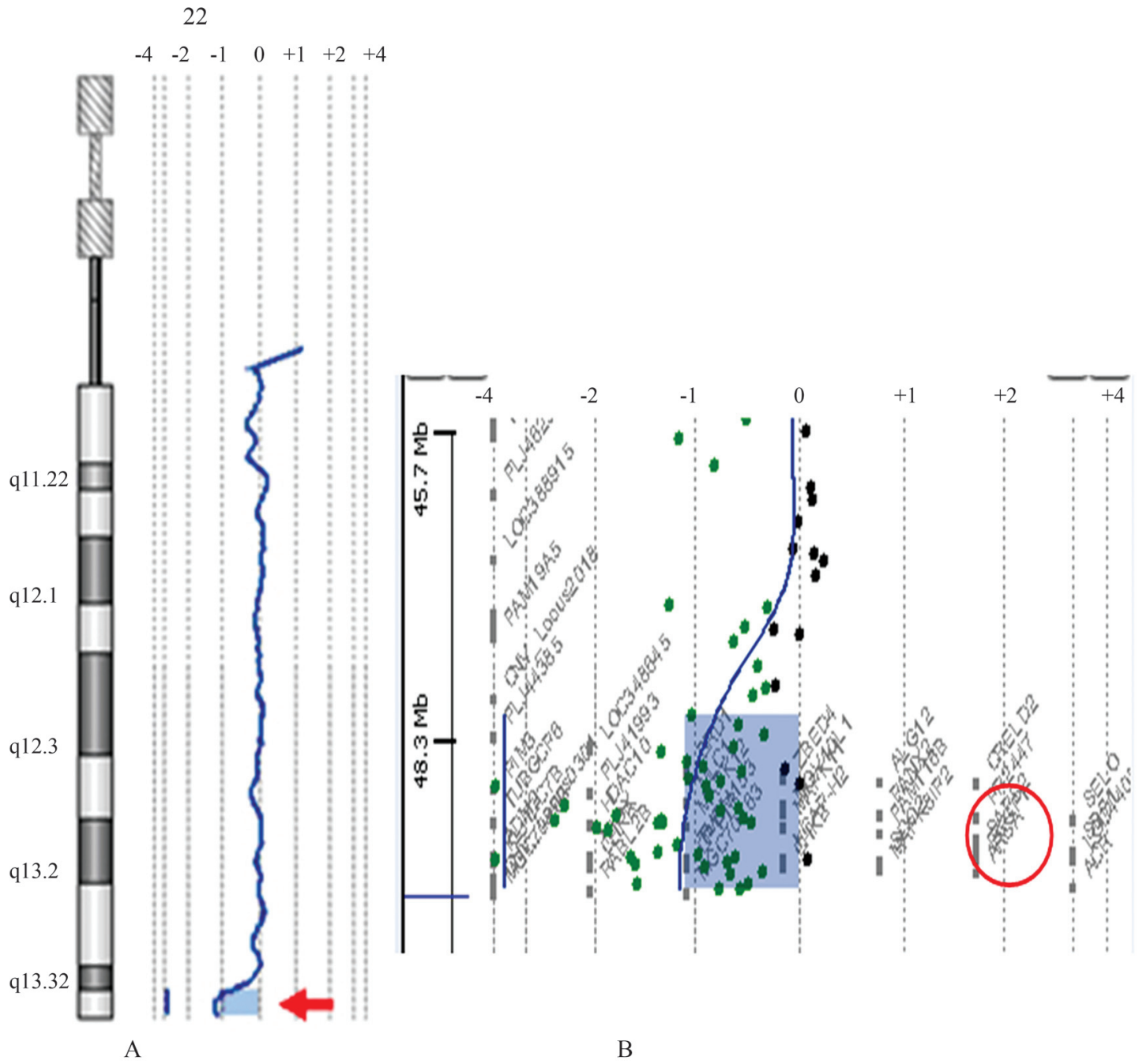

Figure 2 - Chromosome 22 array-CGH profile of the propositus (normal male as a reference DNA). (A) The probe $\log _{2}$ ratios were plotted according to genomic coordinates (based on the UCSC Genome Browser, February 2009, NCBI Build 37 reference sequence). A deletion (copy number loss) was detected on the distal 22q region (red arrow) in a genomic segment with median $\log _{2}$ ratioshifted to $<-0.8$. (B) Detail of the $22 \mathrm{q}$ subtelomeric region showing the deletion of $\sim 1.4 \mathrm{Mb}$ segment which includes the ARSA gene (red circle). The minimum deleted segment was mapped between chr22:48138838 (first aberrant probe) and chr22:49525130 (last aberrant probe).

if the remaining allele is normal (Phelan et al., 1992). If, on the other hand, the remaining allele bears a pathogenic mutation, the patient will present LDM and 22q13 syndrome features (Bisgaard et al., 2009). Defining the cause of low ARSA activity is thus essential for genetic counseling, since the risk of recurrence is negligible in the case of a de novo 22q13 deletion. Moreover, the therapeutic management of low ARSA activity depends on a definitive etiologic diagnosis and may include, as in the case of MLD, bone marrow transplantation and enzyme replacement (Biffi et al., 2008). In the case of the 22q13 deletion syndrome, the use of intranasal insulin is being evaluated (Schmidt et al., 2008).

The case herein reported reinforces the importance of a detailed cytogenetic investigation in patients presenting low arylsulfatase A activity, in association with atypical/unspecific clinical features.

\section{Acknowledgments}

The authors thank Drs. Roberto Giugliani, Louise Lapagesse Pinto, Cristina B. Netto, and Mercedes Villanueva for their help with this study. This study was conducted with the support of FIPE/HCPA, CNPq/Brazil (RedeBRIM Nr. 402012/2010-0) and the Swiss National Foundation (n. 320000-113635).

\section{References}

Artigalás O, Lagranha VL, Saraiva-Pereira ML, Burin MG, Lourenço CM, van der Linden Jr H, Santos ML, Rosemberg S, Steiner CE, Kok F, et al. (2010) Clinical and biochemical study of 29 Brazilian patients with metachromatic leukodystrophy. J Inherit Metab Dis (Epub ahead of print).

Bartsch O, Schneider E, Damatova N, Weis R, Tufano M, Iorio R, Ahmed A, Beyer V, Zechner U and Haaf T (2010) Fulminant hepatic failure requiring liver transplantation in 
22q13.3 deletion syndrome. Am J Med Genet 152:20992102.

Biffi A, Lucchini G, Rovelli A and Sessa M (2008) Metachromatic leukodystrophy: An overview of current and prospective treatments. Bone Marrow Transplant 42:S2-S6.

Bisgaard AM, Kirchhoff M, Nielsen JE, Kibaek M, Lund A, Schwartz M and Christensen E (2009) Chromosomal deletion unmasking a recessive disease: $22 \mathrm{q} 13$ deletion syndrome and metachromatic leukodystrophy. Clin Genet 75:175-179.

Bonaglia MC, Giorda R, Beri S, De Agostini C, Novara F, Fichera M, Grillo L, Galesi O, Vetro A, Ciccone R, et al. (2011) Molecular mechanisms generating and stabilizing terminal 22q13 deletions in 44 subjects with Phelan/McDermid Syndrome. PLoS Genet 7:e1002173.

Durand CM, Betancur C, Boeckers TM, Bockmann J, Chaste P, Fauchereau F, Nygren G, Rastam M, Gillberg IC, Anckarsäter H, et al. (2007) Mutations in the gene encoding the synaptic scaffolding protein SHANK3 are associated with autism spectrum disorders. Nat Genet 39:25-27.

Phelan MC (2008) Deletion 22q13.3 syndrome. Orphanet J Rare Dis 3:14-19.

Phelan MC, Thomas GR, Saul RA, Rogers RC, Taylor HA, Wenger DA and McDermid HE (1992) Cytogenetic, biochemical, and molecular analyses of a 22q13 deletion. Am J Med Genet 43:872-876.

Philippe A, Boddaert N, Vaivre-Douret L, Robel L, Danon-Boileau L, Malan V, de Blois MC, Heron D, Colleaux L, Golse B, et al. (2008) Neurobehavioral profile and brain imaging study of the 22q13.3 deletion syndrome in childhood. Pediatrics 122:376-382.

Schmidt H, Kern W, Giese R, Hallschmid M and Enders A (2008) Intranasal insulin to improve the developmental delay in children with 22q13 deletion syndrome: An exploratory clinical trial. J Med Genet 46:217-222.

Schwartz IV, Ribeiro MG, Mota JG, Toralles MB, Correia P, Horovitz D, Santos ES, Monlleo IL, Fett-Conte AC, Sobrinho RP, et al. (2007) A clinical study of 77 patients with mucopolysaccharidosis type II. Acta Paediatr Suppl 96:6370.

Von Figura K, Gieselmann V and Jaeken J (2001) Methacromatic leukodystrophy. In: Scriver CR, Beaudet AL, Sly WS and Valle D (eds) The Metabolic and Molecular Basis of Inherited Disease. 7th edition. McGraw-Hill, New York, pp 3695-3724.

Waga C, Okamoto N, Ondo Y, Fukumura-Kato R, Goto Y, Kohsaka S and Uchino S (2011) Novel variants of the SHANK3 gene in Japanese autistic patients with severe delayed speech development. Psychiatr Genet 21:208-211.

Wilson HL, Crolla JA, Walker D, Artifoni L, Dallapiccola B, Takano T, Vasudevan P, Huang S, Maloney V, Yobb T, et al. (2008) Interstitial 22q13 deletions: Genes other than SHANK3 have major effects on cognitive and language development. Eur J Hum Genet 16:1301-1310.

\section{Associate Editor: Angela M. Vianna-Morgante}

License information: This is an open-access article distributed under the terms of the Creative Commons Attribution License, which permits unrestricted use, distribution, and reproduction in any medium, provided the original work is properly cited. 